\title{
A novel design of solid oxide fuel cell-based combined cooling, heat and power residential system in the UK
}

\author{
Xinjie Yuan \\ Mechanical Engineering \\ University College London \\ London, United Kingdom \\ xinjie.yuan.15@ucl.ac.uk
}

\author{
Dr Yuanchang Liu \\ Mechanical Engineering \\ University College London \\ London, United Kingdom \\ yuanchang.liu@ucl.ac.uk
}

\author{
Professor Richard Bucknall \\ Mechanical Engineering \\ University College London \\ London, United Kingdom \\ r.bucknall@ucl.ac.uk
}

\begin{abstract}
This paper details the use of objective sizing techniques for a novel design of a residential solid oxide fuel cell (SOFC) combined cooling, heat and electrical power (CCHP) for UK market. The aim of the research is to determine the objective sizing of parameters taking into account the aspects of efficiency, economic and environmental impacts by the entropyweighting approach and grey relationship analysis. The combination of these two approaches helps designers objectively maximise efficiency of energy utilization and minimise emissions and costs of the system that is examined. It is envisaged that electrical demand is met by the fuel cell stacks while the most efficient use is made of heat that is generated by the fuel cell through waste heat recovery to satisfy domestic hot water, freezers, space heating and space cooling. The demand of conventional electric freezers is innovatively designed to be fulfilled by heat exchangers and absorption chillers to further increase the efficiency of heat use. Due to the particularity of the energy demand of the domestic sector in the UK, the proposed system structure, sizing values and control strategies supported by MATLAB R2018a/Simulink - are suited to the residential energy demands of a single household.
\end{abstract}

Keywords-SOFC; CCHP; heat pump; entropy weighting approach; grey relationship

\section{INTRODUCTION}

New dwellings in the domestic sector in the UK require improved conservation measures to attain higher efficiencies in heat use [1]. The adoption of a combined cooling, heating and power (CCHP) system is an advanced method of making the most efficient use of natural resources while reducing demand on the national electricity grid. Considering the lower heat-to-power ratio in the future that would result from a higher degree of thermal insulation in homes [2], domestic fuel cells become a very attractive option [3].

Studies pertaining to fuel cell-based CCHP systems are still at the initial stage. The objectives are mainly related to the performance of the system, namely efficiency, economic and environmental impacts. Single-objective analysis, parametric analysis [4], [5] \& [6] and comparative analysis [7], [8], [9] \& [10] are the most commonly used approaches. For multiobjective analysis, evolutionary algorithms are applied to solve sizing [11], [12] \& [13] and operation strategy [14], [15] $\&[16]$ problems. However, the subjective weight of different objectives applied in these works is largely influenced by the knowledge and experience of designers. In order to help designers objectively maximize efficiency and minimize emissions and costs, objective weighting is introduced in this paper. There are several common methods: the variation coefficient method [17], the principle component analysis [18], the vector similarity measures [19], the grey relationship analysis [20] and the entropy weighting approach [21]. The first three methods require large sample sizes which are not usually available at the initial stage of system design [22]. In comparison, grey system theory enables the analysis of data from a smaller sample size [23]. Therefore, the entropyweighting approach and grey relationship analysis are innovatively combined to determine the objective weighting coefficients.

\section{System AND METhOdOLOGY}

\section{A. Proposed CCHP system}

The combined cooling, heating and power (CCHP) system is designed for a single non-pensioner household in the UK. The household electricity survey from Intertek [24] provides the data of annual domestic electrical product usage. The time series starts from December 2011 and ends in December 2012. Since the sizing values of the system cannot be changed during operation, the design process is conducted according to the largest energy demands of the hottest and coldest days.

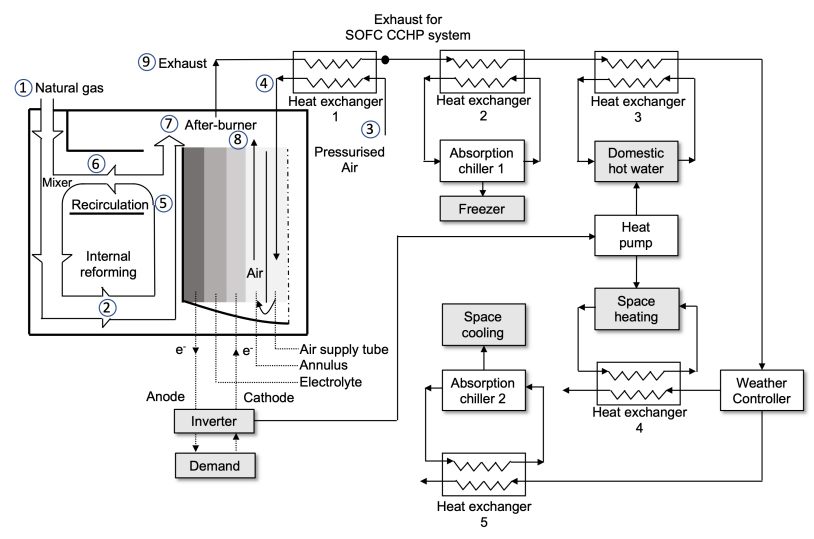

Fig. 1. The illustration of the proposed SOFC-CCHP system.

In Fig. 1, the system is composed of a solid oxide fuel cell (SOFC) system with internal reforming units and heat recovery systems. All the electrical demand is satisfied by the SOFC power output. Heating and cooling demands are fulfilled by a heat pump, heat exchangers and absorption chillers using the waste heat of the SOFC exhaust.

It is assumed that natural gas is the fuel. Part of the exhaust stream leaving the anode (node 5) is recirculated to the internal reforming unit. The remainder - combined with cathodic exhausts - passes through a catalytic after-burner (node 9). The temperature of the exhaust gas is thereby further increased to pre-heat the air inlet (node 3) through heat exchanger 1.

Heat exchanger 2 and absorption chiller 1 are used together to fulfil freezer demand using the waste heat of the exhaust. Domestic hot water demand is provided by heat 
exchanger 3. A weather controller is set to adjust the usage of gases for space heating and cooling. Considering the characteristics of the relatively high heat to power ratio of the coldest day in the UK, waste heat is unable to satisfy all the heating demand when the SOFC is satisfying the electrical load. Therefore, a heat pump, powered by the fuel cell, is applied when necessary.

\section{B. Assumptions}

- Fuel cell modelling is 0-dimension [25], where the current density in the axial direction of the tubular $\mathrm{SOFC}$ is an average value taken as being constant. The fuel cell works in steady state and start-up is not considered.

- It is assumed that polarizations are mainly caused by electrochemical activation barriers, ohmic resistance and concentration polarizations [26].

- Fuel inlet is natural gas and all the methane is consumed in the water gas shift reaction. Fuel utilization factor is assumed to be 0.85 and the air utilization factor is 0.15 [27].

- The effectiveness of the counter-flow heat exchangers [28] and the coefficient of performance (COP) of the absorption chillers [29] are assumed to be between 0.4 and 0.8. The COP of the heat pump is taken as 3 [30].

- It is assumed that there is no heat loss to the surroundings. Thermophysical properties of fluids are assumed constant throughout the heat exchangers.

\section{Constraints and objective functions}

The target sizing values in this project are obtained following two steps: first, determine the number of cells in the fuel cell and then detail the parameters of the heat recovery system.

Step 1: The number of cells cannot be changed during operation. Therefore, the appropriate number of cells is evaluated when all the electrical power, heating and cooling demands are provided by the SOFC electrical system power output. There are four main criteria during the evaluation: integrated efficiency $\left(f_{\text {eff }}\right)$, SOFC cost rate $\left(f_{\text {cost }}\right)$, fuel cost rate $\left(f_{\text {fuel }}\right)$ and emission cost rate $\left(f_{\text {emission }}\right)$.

$$
f_{\text {eff }}=\frac{\sum_{t} \dot{W}_{\text {stack }}}{\sum_{t}\left(\dot{m}_{\text {fuel }} \times L H V\right)_{\text {fuel }, t}}
$$

where $\dot{W}_{\text {stack }}$ is the power output of the SOFC stack, $\dot{m}_{f u e l}$ is the mass flow rate of fuel inlet and LHV is lower heating value of the fuel (the amount of heat released from combustion), and $t$ denotes the time slots of the chosen day.

The total cost rate of capital investment, operating and maintenance for the SOFC, $f_{\text {cost }}$ is evaluated by the formula below [31]:

$$
f_{\text {cost }}=\frac{A_{\text {cell }} \times N_{\text {cell }} \times\left(2.96 \times T_{\text {cell }}-1907\right) \times \frac{i_{r} \times\left(1+i_{r}\right)^{n}}{\left(1+i_{r}\right)^{n}-1} \times \emptyset}{N}
$$

where $A_{\text {cell }}$ and $N_{\text {cell }}$ are the area and number of cells. $T_{\text {cell }}$ is the operating temperature of fuel cell, $i_{r}$ is the interest rate $(12 \%), \emptyset$ denotes the maintenance factor, assumed as $1.1, N$ is the number of system operating hours (8600/year) and $n$ is the system life (20 years) [31].
For the SOFC, the fuel cost rate is another unavoidable parameter that needs to be considered [32]:

$$
f_{f u e l}=c_{f u e l} \times \dot{m}_{f u e l}
$$

where $c_{\text {fuel }}$ is the specific cost per $1 \mathrm{~kg}$ fuel.

The pollution damage from the $\mathrm{CO}_{2}$ emissions is evaluated by multiplying mass flow rate and unit damage cost [32]:

$$
f_{\text {emission }}=c_{\mathrm{CO}_{2}} \times \dot{m}_{\text {fuel }} \times r_{\mathrm{CO}_{2}}
$$

where $\mathrm{C}_{\mathrm{CO}_{2}}$ is the specific damage cost per $1 \mathrm{~kg} \mathrm{CO}_{2}$, and $r_{\mathrm{CO}_{2}}$ is the mass flow rate of $\mathrm{CO}_{2}$ per $1 \mathrm{~kg}$ fuel inlet.

Step 2: The significant parameters of the heat recovery system include the effectiveness of the heat exchangers and the coefficient of performance (COP) of the absorption chillers, the values of which have already been stated. As the heating and cooling demands are satisfied by waste heat and the heat pump, the integrated efficiency $f_{C C H P, \text { eff }}$ is as follows:

$$
f_{C C H P, e f f}=\frac{\dot{W}_{e l e}+\dot{Q}_{h w}+\dot{Q}_{f r e}+\dot{Q}_{s h / s c}}{\dot{m}_{f u e l} \times L H V}
$$

where $\dot{W}_{\text {ele }}, \dot{Q}_{h w}, \dot{Q}_{\text {fre }}$ and $\dot{Q}_{s h / s c}$ are the electrical power, hot water, freezer and space heating demands in winter and summer, respectively.

The formulas for fuel and emission cost rates remain the same. During the evaluation of the parameters of the heat recovery system, the cost rate of the auxiliary components is taken into consideration. It is the sum of the cost rates of the heat exchangers $\left(C_{h x}\right)$ [33] and absorption chillers $\left(C_{a b c}\right)$ [34].

$$
f_{\text {aux }}=\sum_{n} C_{h x, n}+\sum_{m} C_{h x, m}
$$

where $n$ and $m$ are the numbers of heat exchangers and absorption chillers.

$$
\begin{gathered}
C_{h x}=8500+409 \times A_{h x}^{0.85} \\
C_{a b c}=540 \times\left(\frac{\dot{Q}_{a b c}}{1000}\right)^{0.872}
\end{gathered}
$$

where $A_{h x}$ is the area of heat transfer and $\dot{Q}_{a b c}$ is the total energy provided by the absorption chillers. $A_{h x}$ can be evaluated by two common approaches: logarithmic mean temperature difference (LMTD) and effectiveness-number of transfer units ( $\varepsilon$-NTU) methods. LMTD is used when the inlet and outlet temperatures of both hot and cold fluids are known, which is not suitable for this project [35]. By comparison, in this case, $\varepsilon$-NTU [36] can help determine the actual heat transfer rate when only the inlet conditions of the hot and cold fluids are given.

\section{Weighting coefficients in system design}

Grey relationship analysis is an important part of the grey system theory. It quantitatively describes the interaction between factors, of which those with the same trend of development have a closer interconnection [20]. The entropyweighting approach is introduced to reduce the subjectivity during the evaluation and calculation processes [21]. The 
lower the information entropy of a factor, the greater the amount of information that this factor provides, and thus a higher effect on the whole system. The combination of these two methods can help designers objectively determine the importance and weighting coefficients of various factors.

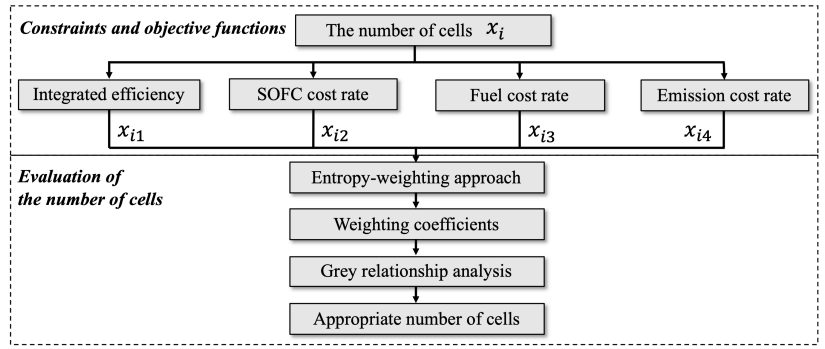

Fig. 2. The flow chart of evaluation of the appropriate number of cells.

From Fig. 2, the evaluation of the appropriate number of cells is done by maximising the integrated efficiency and minimising cost rates, using the entropy-weighting approach and grey relationship analysis. This process is influenced by the four key factors discussed previously, namely by $x_{i 1}$ to $x_{i 4}$. A matrix $(r \times c)$ can be obtained with $c$ eigenvalues, as below.

$\mathrm{X}=\left[\begin{array}{cccc}x_{11} & x_{12} & \cdots & x_{1 c} \\ x_{21} & x_{22} & \cdots & x_{2 c} \\ \vdots & \vdots & \vdots & \vdots \\ x_{r 1} & x_{r 2} & \cdots & x_{r c}\end{array}\right](i=1,2, \cdots r, j=1,2, \cdots c)$

where $x_{i j}$ in Equation (9) denotes the value of the $i^{\text {th }}$ row representing the number of cells, the $j^{\text {th }}$ column representing key factors with $c$ being 4 . The evaluation of parameters of the heat recovery system follows a similar process with different key factors, as discussed previously.

Since different evaluation criteria have various dimensions and units, the matrix should be standardised [20]. For integrated efficiency, the higher value is sought whilst the lower value is better for cost rates. Therefore, for integrated efficiency, it should be standardised as follows:

$$
Y_{i j}=\frac{x_{i j}-\min _{i=1}^{r}\left(x_{i j}\right)}{\max _{i=1}^{r}\left(x_{i j}\right)-\min _{i=1}^{r}\left(x_{i j}\right)}
$$

In comparison, the standardisation of the three cost rates is expressed as follows:

$$
Y_{i j}=\frac{\max _{i=1}^{r}\left(x_{i j}\right)-x_{i j}}{\max _{i=1}^{r}\left(x_{i j}\right)-\min _{i=1}^{r}\left(x_{i j}\right)}
$$

where $\max _{i=1}^{r}\left(x_{i j}\right)$ and $\min _{i=1}^{r}\left(x_{i j}\right)$ are the maximum and minimum values from all the rows of the $j^{\text {th }}$ column.

In this case, conditional entropy $H_{j}$ is the degree of dispersion of the $j^{\text {th }}$ factor conditioned on the discrete random number of cells [37].

$$
H_{j}=-\frac{\sum_{i=1}^{r}\left[\frac{Y_{i j}}{\sum_{i=1}^{i} Y_{i j}} \times \log \left(\frac{Y_{i j}}{\sum_{i=1}^{i} Y_{i j}}\right)\right]}{\log (i)}
$$

where $H_{j}$ is the conditional entropy of the $j^{\text {th }}$ column. However, in this case, it is found that Equation (12) is not a valid expression when $Y_{i j}=0$. Therefore, Equation (13) is added as a constraint condition.

$$
\lim _{\substack{Y_{i j} \\ \sum_{i=1}^{r} Y_{i j}}} \frac{Y_{i j}}{\sum_{i=1}^{r} Y_{i j}} \times \ln \left(\frac{Y_{i j}}{\sum_{i=1}^{r} Y_{i j}}\right)=0, \text { when } \frac{Y_{i j}}{\sum_{i=1}^{r} Y_{i j}}=0 .
$$

With the information entropy values of four columns, the weighting coefficients $w_{j}$ can be calculated as follows [38]:

$$
w_{j}=\frac{1-H_{j}}{c-\sum_{j=1}^{c} H_{j}}
$$

The grey incidence coefficient $\gamma_{i j}$ is regarded as the proximity between the reference sequence $R_{j}$ and the standardised matrix $Y_{i j}[20]$.

$$
\gamma_{i j}=\frac{\min _{i=1}^{r} \min _{j=1}^{c}\left(Y_{i j}-R_{j}\right)+\theta \times \max _{i=1}^{r} \max _{j=1}^{c}\left(Y_{i j}-R_{j}\right)}{\left(Y_{i j}-R_{j}\right)+\theta \times \max _{i=1}^{r} \max _{j=1}^{c}\left(Y_{i j}-R_{j}\right)}
$$

where $\theta$ is the resolution coefficient to decrease the distortion caused by the large value of $\min _{i=1}^{r} \min _{j=1}^{c}\left(Y_{i j}-\right.$ $R_{j}$ ). The degree of distortion is normally taken as 0.5 [20]. The reference sequence $R_{j}$ is the maximum of each column which can be defined as:

$$
R_{j}=\max \left[Y_{1 j}, Y_{2 j}, \cdots, Y_{i j}, \cdots, Y_{c j}\right]
$$

With the weighting coefficients and the grey incidence coefficient calculated above, the overall priority $p_{i}$ of the different number of cells can be expressed as follows [20].

$$
p_{i}=\sum_{j=1}^{c} w_{j} \times \gamma_{i j}
$$

The highest priority value $p_{i}$ indicates the best overall performance of the system considering all the factors.

The modeling and coding process follow the illustration of the proposed system in Fig. 1. A tubular SOFC electrochemical and thermal model is simulated using MATLAB R2018a/Simulink. The model is validated with experimental data [39] \& [40] and verified based on energy and mass balance. The simulation code for the evaluation of appropriate sizing values is implemented in MATLAB R2018a based on the SOFC model.

\section{Results AND Discussions}

This section presents the results of the system design according to the theories discussed in Section II. Validation of the fuel cell unit is conducted before sizing values are obtained. The sizing values include the number of cells and the parameters of the heat recovery system.

\section{A. Validation of fuel cell unit}

In order to validate the fuel cell modelling, the simulated results are compared with two sets of experimental data [39] $\&[40]$ under the same operating temperature of $1273 \mathrm{~K}$. The voltage of a single cell is determined mainly by the structure of the cell, material properties, molar fractions of fuel and water, current density and operating temperatures. Due to the limited available experimental data, data points within the 
range from $150 \mathrm{~mA} / \mathrm{cm}^{2}$ to $500 \mathrm{~mA} / \mathrm{cm}^{2}$ [39] \& [40] are compared in Fig. 3.

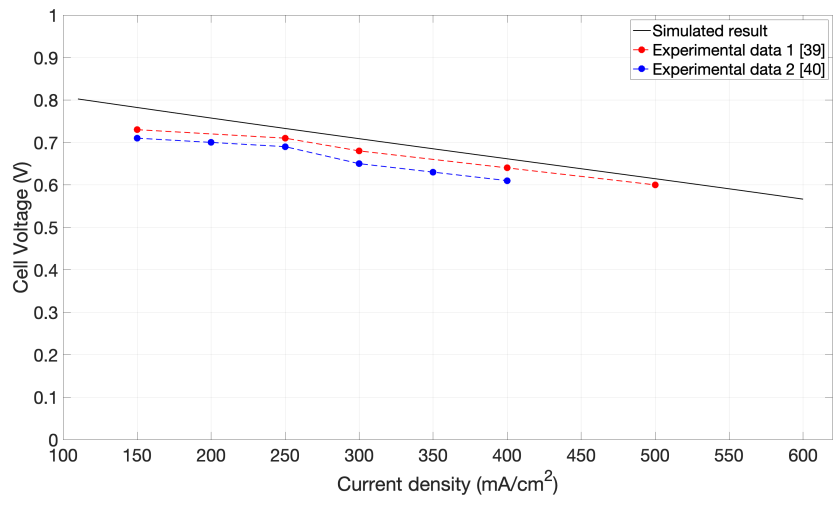

Fig. 3. Comparison of simulated results with experimental data [39] \& [40].

In Fig. 3, with $89 \% \mathrm{H}_{2}$ and $11 \% \mathrm{H}_{2} \mathrm{O}(85 \%$ fuel utilization) as fuel and air as oxidant at $1273 \mathrm{~K}$ [39] \& [40], the relative error agreement is 6 to $8 \%$. The choice of zerodimension modelling is thought to be one of the reasons for this error. In practical experiments, the current density in the axial direction of the tubular SOFC varies influencing the over-voltage values. Another reason is that certain parameters, including the running times of the experiments, are not available. Overall, the model results shown in Fig. 3 corresponds well with the experimental data.

TABLE I. TEMPERATURE AND MOLAR COMPOSITION OF GAES AT NODE No.1 TO No.9 IN FIG. 1.

\begin{tabular}{|c|c|c|c|c|c|c|c|c|}
\hline \multirow{2}{*}{ No. } & \multirow{2}{*}{$\begin{array}{c}\boldsymbol{T}_{\text {cell }} \\
(\mathrm{K})\end{array}$} & \multicolumn{7}{|c|}{ Molar composition (\%) } \\
\cline { 3 - 9 } & $\boldsymbol{H}_{\mathbf{2}}$ & $\boldsymbol{C H}_{\mathbf{4}}$ & $\boldsymbol{C O}$ & $\boldsymbol{C O}_{\mathbf{2}}$ & $\boldsymbol{H}_{\mathbf{2}} \boldsymbol{O}$ & $\boldsymbol{N}_{\mathbf{2}}$ & $\boldsymbol{O}_{\mathbf{2}}$ \\
\hline 1 & 298 & $/$ & 98 & $/$ & $/$ & $/$ & 2 & $/$ \\
\hline 2 & 1014 & 4.88 & 22.92 & 2.97 & 22.40 & 45.86 & 0.97 & $/$ \\
\hline 3 & 298 & $/$ & $/$ & $/$ & $/$ & $/$ & 79 & 21 \\
\hline 4 & 1066 & $/$ & $/$ & $/$ & $/$ & $/$ & 79 & 21 \\
\hline 5 & 1273 & 6.36 & $/$ & 3.87 & 29.25 & 59.86 & 0.66 & $/$ \\
\hline 6 & 1273 & 6.36 & $/$ & 3.87 & 29.25 & 59.86 & 0.66 & $/$ \\
\hline 7 & 1273 & 6.36 & $/$ & 3.87 & 29.25 & 59.86 & 0.66 & $/$ \\
\hline 8 & 1273 & $/$ & $/$ & $/$ & $/$ & $/$ & 81.57 & 18.43 \\
\hline 9 & 1349 & $/$ & $/$ & $/$ & 1.68 & 3.36 & 77.67 & 17.29 \\
\hline
\end{tabular}

In TABLE I, based on energy and mass balances, the molar compositions at nodes 1 to 9 in Fig. 1 can be obtained along with the corresponding temperatures. These are used for the evaluation of the sizing of the fuel cell unit and the heat recovery system.

\section{B. Sizing of fuel cell unit}

The least number of cells is determined by the maximum power demand divided by the maximum power output of a single cell. Since the 24-hour power demand is a given value [24], more cells result in less power output from a single cell. A larger number of cells means higher efficiency and lower fuel and emission cost rates, but higher SOFC cost rates. Objective weights for the four main objectives - integrated efficiency, SOFC cost rate, fuel cost rate and emission cost rate - are $0.1210,0.6576,0.1108$ and 0.1108 . The weighting coefficient of the SOFC cost rate is quite high mainly because it has the strongest dependence on the number of cells.

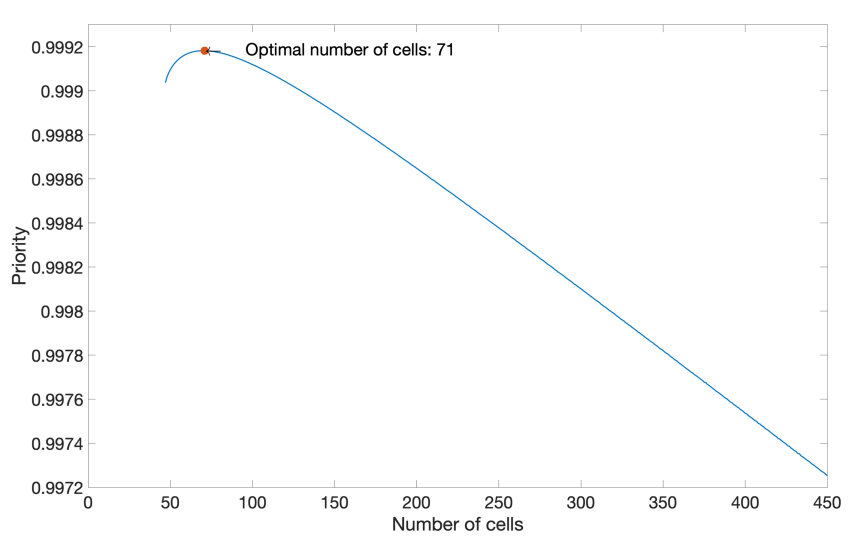

Fig. 4. The illustration priority and the number of cells.

The priority value in Fig. 4 is an index concerning the performance of the whole system based on multi-objective functions. It first increases then decreases when the number of cells grows. When all the factors are considered, while matching the required power demand, the priority is the highest and the integrated efficiency is $60.25 \%$ when the number of cells is 71 . This evaluation lays the foundation for the SOFC-CCHP system.

\section{Sizing of heat exchangers and absorption chillers}

According to the demand on the coldest and hottest days in the UK [24], the sizing values of heat exchangers and absorption chillers are obtained based on the multi-objective functions.

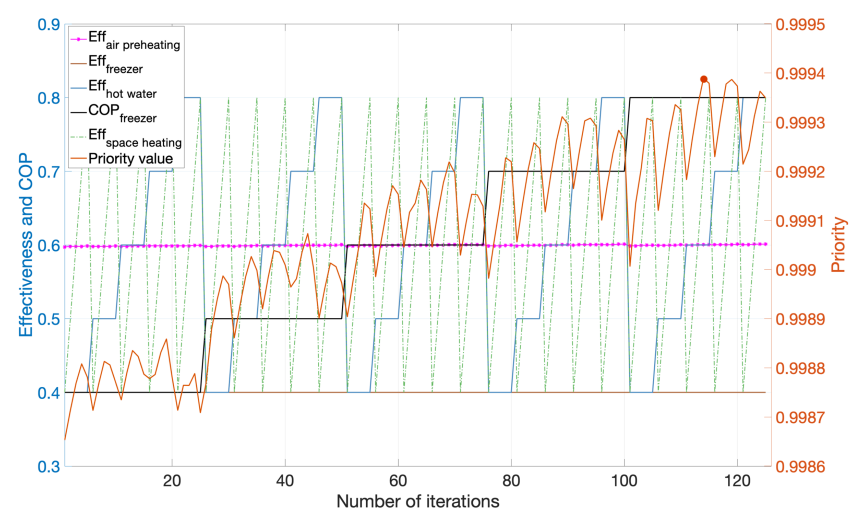

Fig. 5. Priorities of different combination of effectiveness of heat exchangers 1 to 4 and COP of absorption chiller 1 in winter.

From Fig. 5, different combinations of effectiveness of heat exchangers and COP of absorption chillers are evaluated by multi-objective functions. The priority values vary due to the changing effectiveness of the heat exchangers for the freezer, hot water, air pre-heating for the SOFC and the space heating. The weighting coefficients for system efficiency, fuel and emission cost rates and auxiliary component cost rate are $0.2497,0.2503,0.2503$ and 0.2497 . According to the demand on the coldest day, the effectiveness of heat exchangers 1 to 4 are $0.6004,0.4000,0.6000$ and 0.7000 , respectively. The COP of absorption chiller 1 is 0.8000 . The weighting coefficients of objective functions are similar, representing equal significance during the evaluation. The system efficiency reaches $90.96 \%$. Following the similar procedure as before, the effectiveness of heat exchanger 5 and the COP of absorption chiller 2 are 0.4 and 0.6 . The system efficiency is $87.71 \%$. The maximum system efficiency of the SOFC CCHP system on the coldest day is slightly higher than the value 
attained on the hottest day. This is partly because of the characteristics of the mild climate in the UK. The high heating demand on the coldest day results in a higher heat to power demand ratio than on the hottest day. This leads to a higher efficiency in the use of waste heat and a further increase in overall system efficiency.

In this paper, this novel system is taken as a reference system for future work. The system efficiency of the SOFC CCHP system is higher than that of an SOFC electricity-only system. This is mainly caused by exploitation of waste heat. In the electricity-only situation, any heating and cooling needs to be supplied from other sources. There will inevitably be losses associated with these sources. As natural gas has been selected, carbon dioxide is generated during the operation. In the future work, bio natural gas will be used to improve the sustainability and the environmental friendliness of the proposed solution. Besides, the methods applied in this paper could be further modified for various sizes of households under different occupancy profiles considering the aging demographic in the UK. When the system is extended to multiple households, the physical sizes should also considered, for instance as applied to heat exchangers [36].

\section{CONCLUSIONS}

This paper aims to explain the design of a single household fuel cell-based CCHP system using energy consumption data in the UK. Objective weights of various objectives are evaluated as it is a multi-objective design problem to avoid inaccurate human judgement. The number of cells, effectiveness of heat exchangers, COP of absorption chillers are determined to objectively maximise system efficiency and to minimise costs and emissions. The number of cells is set as 71. The effectiveness of 5 heat exchangers are $0.6004,0.4000$, $0.6000,0.7000$ and 0.4000 . The COP of absorption chillers 1 and 2 are 0.8000 and 0.6000 . The maximum efficiency of the SOFC electrical-only system is $60.25 \%$. The system efficiency attains $90.96 \%$ and $87.71 \%$ on the coldest and hottest days, respectively.

\section{ACKNOWLEDGMENT}

The first author would like to thank China Scholarship Council (CSC) for supporting his studies at UCL. Thanks to Mr Konrad Yearwood for proof reading and valuable advice.

\section{REFERENCES}

[1] HM Government, "Conservation of fuel and power in existing dwellings," UK Build. Regul., vol. L1B, pp. 1-48, 2018.

[2] BEIS, "Energy Consumption in the UK (ECUK) 2018," Energy Consum. UK, no. July, pp. 1-39, 2018.

[3] A. Arsalis, M. P. Nielsen, and S. K. Kær, "Application of an improved operational strategy on a PBI fuel cell-based residential system for Danish single-family households," Appl. Therm. Eng., vol. 50, no. 1, pp. 704-713, 2013.

[4] M. Chahartaghi and B. A. Kharkeshi, "Performance analysis of a combined cooling, heating and power system with PEM fuel cell as a prime mover," Appl. Therm. Eng., vol. 128, pp. 805-817, 2018.

[5] H. Zhang, W. Kong, F. Dong, H. Xu, B. Chen, and M. Ni, "Application of cascading thermoelectric generator and cooler for waste heat recovery from solid oxide fuel cells," Energy Convers. Manag., vol. 148, pp. 1382-1390, 2017.

[6] H. Chang et al., "Energy- and exergy-based working fluid selection and performance analysis of a high-temperature PEMFC-based micro combined cooling heating and power system," Appl. Energy, vol. 204, pp. 446-458, 2017.

[7] F. Calise, R. D. Figaj, N. Massarotti, A. Mauro, and L. Vanoli, "Polygeneration system based on PEMFC, CPVT and electrolyzer: Dynamic simulation and energetic and economic analysis," Appl.
Energy, vol. 192, pp. 530-542, 2017.

[8] V. Palomba, M. Prestipino, and A. Galvagno, "Tri-generation for industrial applications: Development of a simulation model for a gasification-SOFC based system," Int. J. Hydrogen Energy, vol. 42, no. 46, pp. 27866-27883, 2017.

[9] A. L. Facci, V. Cigolotti, E. Jannelli, and S. Ubertini, "Technical and economic assessment of a SOFC-based energy system for combined cooling, heating and power," Appl. Energy, vol. 192, no. 2017, pp. 563-574, 2017.

[10] A. Chitsaz, J. Hosseinpour, and M. Assadi, "Effect of recycling on the thermodynamic and thermoeconomic performances of SOFC based on trigeneration systems; A comparative study," Energy, vol. 124, pp. 613-624, 2017.

[11] R. Jing, M. Wang, N. Brandon, and Y. Zhao, "Multi-criteria evaluation of solid oxide fuel cell based combined cooling heating and power (SOFC-CCHP) applications for public buildings in China," Energy, vol. 141, pp. 273-289, 2017.

[12] E. Baniasadi and A. A. Alemrajabi, "Fuel cell energy generation and recovery cycle analysis for residential application," Int. J. Hydrogen Energy, vol. 35, no. 17, pp. 9460-9467, 2010.

[13] P. Arcuri, P. Beraldi, G. Florio, and P. Fragiacomo, "Optimal design of a small size trigeneration plant in civil users: A MINLP (Mixed Integer Non Linear Programming Model)," Energy, vol. 80, pp. 628$641,2015$.

[14] S. Soheyli, M. Mehrjoo, and M. H. Shafiei Mayam, "Modeling and optimal resources allocation of a novel tri-distributed generation system based on sustainable energy resources," Energy Convers. Manag., vol. 143, pp. 1-22, 2017.

[15] Z. Li and Y. Xu, "Optimal coordinated energy dispatch of a multienergy microgrid in grid-connected and islanded modes," Appl. Energy, vol. 210, no. August 2017, pp. 974-986, 2018.

[16] A. Baghernejad, M. Yaghoubi, and K. Jafarpur, "Exergoeconomic comparison of three novel trigeneration systems using SOFC, biomass and solar energies," Appl. Therm. Eng., vol. 104, pp. 534-555, 2016.

[17] H. P. Zheng, M. Xue, Y. Han, and W. C. Zhang, "Application of the Variation Coefficient Method to Comprehensive Evaluation of Wind Farms," in Applied Mechanics and Materials, 2014, vol. 488, pp. 1447-1453.

[18] A. Bai, S. Hira, and P. S. Deshpande, "An application of factor analysis in the evaluation of country economic rank," Procedia Comput. Sci., vol. 54, pp. 311-317, 2015.

[19] Y. Song and J. Hu, "Vector similarity measures of hesitant fuzzy linguistic term sets and their applications," PLoS One, vol. 12, no. 12, p. e0189579, 2017.

[20] Y. Cenglin, "Application of Gray Relational Analysis Method in Comprehensive Evaluation on the Customer Satisfaction of Automobile 4S Enterprises," Phys. Procedia, vol. 33, pp. 1184-1189, 2012.

[21] R. Gu, "Multiscale Shannon entropy and its application in the stock market," Phys. A Stat. Mech. its Appl., vol. 484, pp. 215-224, 2017.

[22] J. J. Shuai and W. W. Wu, "Evaluating the influence of E-marketing on hotel performance by DEA and grey entropy," Expert Syst. Appl., vol. 38, no. 7, pp. 8763-8769, 2011.

[23] M. L. Tseng, "A causal and effect decision making model of service quality expectation using grey-fuzzy DEMATEL approach," Expert Syst. Appl., vol. 36, no. 4, pp. 7738-7748, 2009.

[24] J.-P. Zimmermann et al., "Household Electricity Survey: A study of domestic electrical product usage," Intertek, p. 600, 2012.

[25] M. Karcz, "From OD to 1D modeling of tubular solid oxide fuel cell," Energy Convers. Manag., vol. 50, no. 9, pp. 2307-2315, 2009.

[26] G. Kaur, Solid oxide fuel cell components: Interfacial compatibility of SOFC glass seals. 2015.

[27] P.-W. Li and K. Suzuki, "Numerical Modeling and Performance Study of a Tubular SOFC," J. Electrochem. Soc., vol. 151, no. 4, p. A548, 2004.

[28] A. Bejan, M. Alalaimi, S. Lorente, A. S. Sabau, and J. W. Klett, "Counterflow heat exchanger with core and plenums at both ends," Int. J. Heat Mass Transf., vol. 99, pp. 622-629, 2016.

[29] M. A. Abd Majid, S. A. Sulaiman, T. Fujii, and Naono, "Studies on Steam Absorption Chillers Performance at a Cogeneration Plant," MATEC Web Conf., vol. 13, p. 05003, 2014.

[30] V. Trillat-Berdal, B. Souyri, and G. Fraisse, "Experimental study of a ground-coupled heat pump combined with thermal solar collectors," Energy Build., vol. 38, no. 12, pp. 1477-1484, 2006. 
[31] L. Khani, S. M. S. Mahmoudi, A. Chitsaz, and M. A. Rosen, "Energy and exergoeconomic evaluation of a new power/cooling cogeneration system based on a solid oxide fuel cell," Energy, vol. 94, pp. 64-77, 2016.

[32] P. Ahmadi and I. Dincer, "Thermodynamic analysis and thermoeconomic optimization of a dual pressure combined cycle power plant with a supplementary firing unit," Energy Convers. Manag., vol. 52, no. 5, pp. 2296-2308, 2011.

[33] H. Sadeghzadeh, M. Aliehyaei, and M. A. Rosen, "Optimization of a finned shell and tube heat exchanger using a multi-objective optimization genetic algorithm," Sustain., vol. 7, no. 9, pp. 11679$11695,2015$.

[34] H. Hajabdollahi, "Investigating the effects of load demands on selection of optimum CCHP-ORC plant," Appl. Therm. Eng., vol. 87, pp. 547-558, 2015.

[35] X. Cui, K. J. Chua, M. R. Islam, and W. M. Yang, "Fundamental formulation of a modified LMTD method to study indirect evaporative heat exchangers," Energy Convers. Manag., vol. 88, pp. 372-381, 2014.

[36] H. A. Navarro and L. C. Cabezas-Gómez, "Effectiveness-ntu computation with a mathematical model for cross-flow heat exchangers," Brazilian J. Chem. Eng., vol. 24, no. 4, pp. 509-521, 2007.

[37] S. U. Xuan, X. WANG, Z. WANG, and Y. XIAO, "An New Fuzzy Clustering Algorithm Based on Entropy Weighting," J. Comput. Inf. Syst., vol. 6, no. 10, pp. 3319-3326, 2010.

[38] Z. Zhang and J. David, "An entropy-based approach for assessing the operation of production logistics," Expert Syst. Appl., vol. 119, pp. 118-127, 2019.

[39] S. C. Singhal, "Advances in Tubular Solid Oxide Fuel Cell Technology," 1996 Fuel Cell Semin., vol. 135, pp. 28-31, 1996.

[40] M. J. Carl, "SOFC Modeling for the Simulation of Residential Cogeneration Systems," 2008. 